Corrigendum

\title{
Corrigendum to "Indicators of Quality of Clinical Care for Type 2 Diabetes Patients in Primary Health Care Centers in Qatar: A Retrospective Analysis"
}

\author{
Saleh Attal $\mathbb{C}^{1},{ }^{1}$ Mohamed H. Mahmoud, ${ }^{1}$ Muna Taher Aseel, ${ }^{1}$ Ady Candra, ${ }^{1}$ Paul Amuna, \\ Mohamed Elnagmy, ${ }^{1}$ Mostafa Abdallah, ${ }^{1}$ Nahed Ismail, ${ }^{1}$ Ahmed Hanfy, ${ }^{1}$ Dia Albaw, \\ Abdulsalam Albashir, ${ }^{1}$ and Hisham Elmahdi ${ }^{1}$ \\ ${ }^{1}$ Family Medicine Residency Program, Primary Health Care Corporation, West Bay Training Center, Doha, Qatar \\ ${ }^{2}$ Research Department, Primary Health Care Corporation, Doha, Qatar \\ Correspondence should be addressed to Saleh Attal; alatalsaleh@yahoo.com
}

Received 22 August 2020; Accepted 22 August 2020; Published 31 October 2020

Copyright $(2020$ Saleh Attal et al. This is an open access article distributed under the Creative Commons Attribution License, which permits unrestricted use, distribution, and reproduction in any medium, provided the original work is properly cited.

In the article titled "Indicators of Quality of Clinical Care for Type 2 Diabetes Patients in Primary Health Care Centers in Qatar: A Retrospective Analysis" [1], the name of the author Ahmed Hanfy was given incorrectly as Ahmed Abdelrazek. The revised authors' list is shown above.

\section{References}

[1] S. Attal, M. H. Mahmoud, M. Taher Aseel et al., "Indicators of quality of clinical care for type 2 diabetes patients in primary health care centers in Qatar: a retrospective analysis," International Journal of Endocrinology, vol. 2019, Article ID 3519093, 9 pages, 2019. 